\title{
Interactions between allelochemicals and the microbial community affect weed suppression following cover crop residue incorporation into soil
}

\author{
Yi Lou • Adam S. Davis • Anthony C. Yannarell
}

Received: 27 March 2015 / Accepted: 29 September 2015 /Published online: 15 October 2015

(C) The Author(s) 2015. This article is published with open access at Springerlink.com

\begin{abstract}
Background and aims The objective of this study is to understand how soil microorganisms interact with cover crop-derived allelochemicals to suppress weed germination and growth following cover crop residue incorporation.

Methods We conducted a time series experiment crossing sterilized and non-sterilized soil with four different residue treatments. We measured weed seed germination rates, radicle elongation, and disease incidence in seed germination bioassays. We also monitored cover crop-derived, isoflavone allelochemicals in these bioassays. We partitioned the total weed suppression into three sources: microbe-only inhibition, residue-only inhibition, and the microbe-residue interaction.

Results Microbial activity suppressed weed germination and growth for 30 days, while cover crop-derived allelochemicals provided suppression for a limited time. There was an antagonistic interaction between microbes and allelochemicals. This interaction was strongest for
\end{abstract}

Responsible Editor: Leslie A. Weston.

Electronic supplementary material The online version of this article (doi:10.1007/s11104-015-2698-8) contains supplementary material, which is available to authorized users.

Y. Lou · A. C. Yannarell $(\bowtie)$

Department of Natural Resources and Environmental Sciences, University of Illinois at Urbana-Champaign, Urbana, IL, USA e-mail: acyann@illinois.edu

A. S. Davis

USDA-ARS, Global Change and Photosynthesis Research Unit, Urbana, IL, USA water-soluble allelochemicals, while residue fractions containing intact plant tissues retained greater suppressiveness even in the presence of a live microbial community.

Conclusions Microbial activity can directly suppress weed germination and growth, but microorganisms also indirectly help weeds by degrading cover crop-derived allelochemicals. As a result of these interactions, cover crop-derived weed suppression in agricultural soils shifts from an early allelochemical-dominated phase to a later phase where microbial suppression is more important.

Keywords Allelochemicals · Isoflavones · Red clover (Trifolium pratense L.) · Soil microbes · Weed suppression · Wild mustard (Sinapis alba L.)

\section{Abbreviations \\ GI Germination inhibition \\ RI Radicle elongation inhibition \\ PLSR Partial least squares regression}

\section{Introduction}

Because widespread herbicide use in agriculture leads to environmental damage and increased emergence of herbicide-resistant weeds, there is much interest in alternative forms of weed control (Charudattan 2001; Inderjit et al. 2005; Liebman and Davis 2009; Weston 1996). Rotations involving cover crops are examples of weed suppression tactics that can contribute to 
alternative, integrated weed management systems (Liebman and Davis 2000; Liebman and Davis 2009; Wortman et al. 2013). Cover crops can suppress weeds through resource and light competition (Liebman and Dyck 1993; Teasdale 1996), disruption of weed life cycles (Moyer et al. 2000), physical suppression by cover crop residues (Moore et al. 1994), and release of phytotoxic chemicals associated with cover crop residues (Kruidhof et al. 2009; Samedani et al. 2013; Teasdale et al. 2012). These cover crop residueassociated allelochemicals can suppress weed seed germination (Seigler 1996), seedling establishment (Singh et al. 2003; Weston 1996), and weed growth rates (Mirsky et al. 2011; Wardle 1995).

The total allelochemical potential of a cover crop residue is a combination of water-soluble phytotoxins released by residues prior to decomposition, as well as the insoluble phytotoxins released by microorganisms during decomposition (Barnes and Putnam 1986; Harper and Lynch 1982) and the subsequent microbial transformation of these phytotoxins (Barnes and Putnam 1986; Inderjit 2005). Microbes can deactivate watersoluble allelochemicals released soon after cover crop residue incorporation (Jilani et al. 2008), but they can also transform harmless plant-derived compounds to more toxic forms (Williamson et al. 1992). Microbes play important roles in releasing additional allelochemicals bound up in the recalcitrant fractions of cover crop residues (Barnes et al. 1987). These insoluble allelochemicals can constitute a significant fraction of total allelopathic potential of a cover crop residue (Harper and Lynch 1982), so microbes may slowly release residue-derived allelochemicals, extending the longevity of a cover crop's effectiveness. Given that agricultural soils are not sterile, it is important to understand how microbial activity moderates allelochemical potential of cover crop residues (Inderjit 2005; Inderjit et al. 2005).

In addition to their effects on allelochemicals, soilborne microbial antagonists can provide biological forms of weed suppression. Various pathogenic strains with weed control potential have been isolated from soil or infected weed seedlings (Kremer 1993). Pathogenic infection of weeds can reduce weed germination rates and retard the growth of seedlings (Davis and Renner 2007). Cover crop residues may enhance soil pathogen growth (Conklin et al. 2002; Mohler et al. 2012) and potentially encourage pathogens to attack damaged weed seedlings (Chandler and Daniell 1974; Patrick et al. 1964). Mohler and colleagues recently showed that unsterilized "live" soil (i.e., with a natural microbial community) reduces seedling germination rates when cover crop residues are incorporated, and the combined effect of residues and live microorganisms is greater than the effect of either of these components alone (Mohler et al. 2012). Exposure to cover crop-derived allelochemicals increases the density of fungal lesions on plant seedlings (Toussoun and Patrick 1963). Furthermore, disease incidence on seedlings and the abundance of soilborne pathogens can both be increased with cover crop residue addition to soils (Conklin et al. 2002; Rothrock and Kirkpatrick 1995). Thus, it is reasonable to suspect that disease-causing microorganisms may provide a leverage point for more effective weed suppression potential.

The dynamics of cover crop- and microorganismderived weed suppression will depend on the rate of allelochemical release, the properties of the allelochemicals, and the activities of allelochemicaldegrading and seedling-infecting microorganisms. These factors interact to create a "window" of weed suppression potential. Residue-induced suppression of a sensitive plant will take place only when there is an overlap in time between the period of sensitivity of the plant and the window of the suppression potential (Kruidhof et al. 2009). Microbial activity may reduce the length of this window if microbe-allelochemical interactions are antagonistic, but microbial activity may extend this window if these interactions are synergistic. Here, we characterize the weed-suppressive capacity of different soluble and insoluble fractions of cover crop residues. We examine the temporal dynamics of weed suppression over time in the presence and absence of a live soil community in order to determine whether microbial activity is synergistic or antagonistic with cover crop-derived allelochemicals and in order to describe how this interaction changes over time. We hypothesize that microbial activity will be synergistic with cover crop residues because (1) microbial decomposition will release bound allelochemicals from solid residues, and (2) cover crop-derived residues will stimulate pathogen attack of germinating seedlings.

\section{Materials and methods}

Preparation of red clover residue fractions and soil treatments

For our cover crop, we selected Mammoth red clover (Trifolium pratense), a widely used legume cover crop 
with high allelochemical potential (Liebman and Sundberg 2006a). We planted red clover in April 2013 at the Maxwell Trust site of the Crop Sciences Research and Education Center, Urbana, IL, in a field plot that had been maintained in a corn-soybean rotation for over 20 years. The soil at the field was a Catlin silt loam (Oxyaquic Argiudoll) with the following characteristics: $7 \%$ sand, $68 \%$ silt, $25 \%$ clay, and $4.2 \%$ soil organic carbon, $\mathrm{pH} 7.2$. We harvested the aerial portions of red clover plants at the bud stage after 14 weeks of growth.

We processed the red clover shoots and leaves in order to evaluate the weed-suppressive potential of three different residue-derived fractions: (1) the water-soluble fraction, (2) the insoluble faction (i.e., bound in the "straw"), and (3) the fresh residue fraction (which contained both the soluble and insoluble components). The fresh residue fraction was intended to mimic additions of red clover residues in a typical "green manure" management strategy, in which cover crop residues are mixed into soil surface layers, while the water-soluble and straw fractions were intended to allow us to identify the separate contributions of soluble and insoluble allelochemicals (Creamer et al. 1996). Plants destined for the fresh residue treatments were stored at $4{ }^{\circ} \mathrm{C}$ for no more than 1 week prior to use in the bioassays described below. The other plants were freeze-dried to facilitate the extraction of water-soluble allelochemicals. We used freeze drying because it can best preserve the original forms of isoflavones in red clover as compared to oven drying (Tsao et al. 2006). We cut $20 \mathrm{~g}$ of the freeze-dried tissues into 5 -cm pieces and shook them in $400 \mathrm{ml}$ sterilized, deionized water for $16 \mathrm{~h}$ at $23^{\circ} \mathrm{C}$. We used cheesecloth to recover the large pieces of residue, and then, we centrifuged $(4000 \times g, 10 \mathrm{~min})$ the liquid fraction to further remove particulate matter. We concentrated the liquid fraction, containing the readily available, water-soluble chemicals, fivefold by freezedrying the extract to a final volume of $80 \mathrm{ml}$. We stored the resulting concentrated extract at $-20{ }^{\circ} \mathrm{C}$ for use in the bioassays described below. The large red clover pieces recovered from the cheesecloth were redried in a freeze dryer and stored at $4{ }^{\circ} \mathrm{C}$ until their use in bioassays described below. We refer to these waterextracted residues as the straw fraction, which have been leached of readily available water-soluble chemicals.

We collected soil for the bioassays in June 2013 from the same field where red clover was planted, to a depth of $10 \mathrm{~cm}$. We collected bulk soil with a trowel, passed the soil through a $2 \mathrm{~mm}$ sieve, and stored the soil in a sealed plastic bucket at $4{ }^{\circ} \mathrm{C}$ for up to 1 month before use. We divided this soil into two portions, one of which was triple-autoclaved at $120{ }^{\circ} \mathrm{C}$ for $1 \mathrm{~h}$ to kill soil microorganisms.

\section{Experimental design}

We combined microbial treatments (live vs. sterilized soil) and red clover fractions (fresh residues, watersoluble extracts, straw fraction, and water-only controls) in a fully factorial experiment. We constructed 480 mesocosms in Magenta vessels (GA-7 vessels $(77 \mathrm{~mm} \times 77 \mathrm{~mm} \times 97 \mathrm{~mm})$ from Sigma-Aldrich Co. St. Louis, MO) to represent the two microbial $\times$ four residue fraction $\times$ six time point (see below) combinations (ten replicate mesocosms, each). Fresh red clover and straw fractions were completely dispersed in a plastic bag with a zipper closure and sterilized by UV light for $2 \mathrm{~h}$ on each side prior to addition to the mesocosms in order to control for the introduction of microorganisms present on the plant tissue (Wilson et al. 1999). We filter-sterilized extracts through a $0.22-\mu$ filter prior to addition to mesocosms. Because $2 \%$ red clover was sufficient to elicit a germination response in mustard seeds (Liebman and Sundberg 2006b) and was similar to field incorporation rates of red clover (Dyck and Liebman 1995), we added $2 \%$ (by weight) fresh red clover residues, or the equivalent amount of potentially bioactive compounds, to each mesocosm. Each mesocosm contained $110 \mathrm{~g}$ of soil. Therefore, we added $(110 \mathrm{~g} \times 2 \%=) 2.2 \mathrm{~g}$ of fresh red clover residue cut into $5-\mathrm{cm}$ pieces to all fresh residue treatment mesocosms. The freeze-drying procedure used to produce the watersoluble extract and straw residue fractions (see above) resulted in a sixfold reduction in the mass of straw residues in comparison to the fresh litter. Therefore, we added $(2.2 \mathrm{~g} \times 6=) 13.2 \mathrm{~g}$ of straw residues to all straw residue treatment mesocosms. We added the equivalent amount of water-soluble extracts found in $2.2 \mathrm{~g}$ of fresh residue to our water-soluble extract treatment mesocosms; we had extracted $20 \mathrm{~g}$ of fresh residues into a final volume of $80 \mathrm{ml}$ water (see above), and thus, we added $(2.2 \mathrm{~g}$ residue $\times 80 \mathrm{ml} / 20 \mathrm{~g}$ residue $=)$ $8.8 \mathrm{ml}$ of extract. Finally, we added $8.8 \mathrm{ml}$ of double-distilled water to our water-only treatment mesocosms. Mesocosms were fitted with lids with a filter-covered hole to maintain sterile conditions and minimize water loss. 
All mesocosms were set up on the same day, but we assayed their weed suppression potential at different times in order to understand how weed suppression changes with time after residue incorporation. We conducted these assays at days $0,2,4,8,16$, and 30 . At each of these time points, we randomly selected ten replicate mesocosms from each of the eight microbe $\times$ residue fraction treatments ( 80 mesocosms, in all) and used all of the soil in each mesocosm to conduct the bioassays described below. Mesocosms were arranged in a glasshouse according to a fully randomized design, and we rerandomized the placement of the remaining mesocosm after each assay time points.

Bioassays of germination and seedling growth

We used the seed germination bioassay technique of Dabney and colleagues (1996), as described below, to assess the microbial and allelochemical effects on weed germination and growth at each of the six time points described above. We used IdaGold mustard (Sinapis alba L.) as a model weed because wild brassicaceae are common weeds of temperate agroecosystems (e.g., wild mustard (Sinapis arvensis) and yellow rocket (Barbarea vulgaria)). IdaGold mustard is the cultivated variety of $S$. alba, and it has a very high, uniform germination rate. Therefore, seed dormancy was unlikely to be a factor in our estimation of seed germination. Before the bioassay began, $10 \mathrm{~g}$ soil were collected into separate centrifuge tubes and stored at $-20^{\circ} \mathrm{C}$ for analysis of soil phenolic carbon content (see below).

Each bioassay unit was constructed from a different, single mesocosm. We placed 15 mustard seeds in a line $10 \mathrm{~cm}$ from the top edge a double layer of 25 by $38 \mathrm{~cm}$ germination paper (Anchor Paper, St. Paul, MN) moistened with $20 \mathrm{ml}$ of sterilized, deionized water. Then, we spread the remaining $100 \mathrm{~g}$ of soil from a mesocosm in a 12-cm-wide band, about $6 \mathrm{~cm}$ from the top edge of germination paper, to cover the line of seeds. We placed another moistened sheet of germination paper on top of the seeds and soil and rolled this entire assembly from the short edge to create a cylinder. We wrapped and sealed each cylinder in a plastic zip-lock bag to maintain soil moisture content throughout the bioassay. We incubated these bioassay units vertically (i.e., with seeds oriented "up" in the upright cylinder) in a Conviron 125L incubator (Controlled Environments Limited, Manitoba, Canada) for 7 days with a $16 \mathrm{~h} \mathrm{light} / 8 \mathrm{~h}$ dark cycle (25 and $20^{\circ} \mathrm{C}$, respectively).
After 7 days of incubation, we deconstructed each bioassay unit and recorded the number of germinating seeds and the radicle length of all germinated seedlings. We also recorded the number of seedlings with visible necrotic lesions on the radicle, which we considered to be infected for the purposes of this study.

Soil total phenolic extraction and measurement

Total phenolic compounds are often used as a proxy for plant-derived allelochemicals (Inderjit 1996; Ohno et al. 2000). We estimated the phenolic content of mesocosm soils at the time that each was used to construct the bioassays (collected upon setup, as described above) using the methods of Levengood and colleagues (2010) with the following modifications. We ground soils with a mortar and pestle, and we transferred $5 \mathrm{~g}$ to a 50-ml centrifuge tube. We extracted soils twice with $20 \mathrm{ml}$ of 25:70:5 acetonitrile/methanol/acetone for $2 \mathrm{~h}$ with vigorous shaking. Between extractions, we centrifuged samples $(4000 \times \mathrm{g}, 10 \mathrm{~min})$ and retained the supernatant. We combined the supernatants and reduced the volume to approximately $2 \mathrm{ml}$ with nitrogen flow and heating to $37{ }^{\circ} \mathrm{C}$. We used the Folin-Ciocalteu method (Ainsworth and Gillespie 2007) to quantify total soil phenolics from these extracts as follows. We mixed $0.1 \mathrm{ml}$ of extract with $0.2 \mathrm{ml}$ of $1: 10$ diluted FolinCiocalteu's phenol reagent and $0.8 \mathrm{ml}$ of $700 \mathrm{~nm}$ sodium carbonate and incubated for $2 \mathrm{~h}$ at $23{ }^{\circ} \mathrm{C}$. We then measured absorbance at $765 \mathrm{~nm}$ using gallic acid standards to create a standard curve.

\section{HPLC analysis}

Isoflavones are the main allelopathic compounds in red clover (Macias et al. 2007). We used HPLC to analyze the total soil phenolic extracts for nine main isoflavones in red clover (Krenn et al. 2002). They are biochanin A, calycosin, daidzein, daidzin, formononetin, genistein, genistin, glycitein, and prunetin. We did not determine the extraction efficiency of our techniques in this soil. As only a single soil source was used to establish all treatments, we make the assumption that the extraction efficiency was the same in all samples, and we used HPLC to look for relative changes in isoflavone composition between treatments and over time. Samples were analyzed with Metabolomics Center's 5500 QTRAP LC/MS/MS system (AB Sciex, Foster City, CA) with a 1200 series HPLC system (Agilent 
Technologies, Santa Clara, CA) including a degasser, an autosampler, and a binary pump. The LC separation was performed on a Bidentate C18 100A column $(2.1 \times$ $150 \mathrm{~mm}, 4 \mu \mathrm{m}$ ) (MicroSolv Technology Corp. Eatontown, $\mathrm{NJ})$ with mobile phase A $(0.1 \%$ formic acid in water) and mobile phase B $(0.1 \%$ formic acid in acetonitrile). The flow rate was $0.4 \mathrm{ml} / \mathrm{min}$. The linear gradient was as follows: $0-1 \mathrm{~min}, 90 \% \mathrm{~A} ; 15 \mathrm{~min}$, $80 \% \mathrm{~A}$; 25-35 min, $67 \% \mathrm{~A}$; 40-42 min, $50 \% \mathrm{~A}$; 42.5-48 min, $90 \% \mathrm{~A}$. The autosampler was set at $5{ }^{\circ} \mathrm{C}$. The injection volume was $2 \mu \mathrm{L}$. Mass spectra were acquired in the positive mode with ion spray voltage of $5500 \mathrm{~V}$. The source temperature was $450{ }^{\circ} \mathrm{C}$. The curtain gas, ion source gas 1 , and ion source gas 2 were 35, 65, and 55 psi, respectively. Multiple reaction monitoring (MRM) was used for quantitation: daidzin $\mathrm{m} / \mathrm{z}$ 417.1- $\mathrm{m} / \mathrm{z}$ 255.0, genistin $\mathrm{m} / \mathrm{z} 433.1-\mathrm{m} / \mathrm{z}$ 271.0, daidzein $\mathrm{m} / \mathrm{z} 255.0-\mathrm{m} / \mathrm{z}$ 199.0, glycitein $\mathrm{m} / \mathrm{z}$ $285.0-\mathrm{m} / \mathrm{z} 270.1$, calycosin $\mathrm{m} / \mathrm{z} 285.0-\mathrm{m} / \mathrm{z} 270.1$, genistein $\mathrm{m} / \mathrm{z} 271.1-\mathrm{m} / \mathrm{z}$ 153.0, formononetin $\mathrm{m} / \mathrm{z} 269.1-\mathrm{m} / \mathrm{z}$ 213.0, prunetin $m / z$ 285.1- $\mathrm{m} / \mathrm{z} 242.0$, biochanin A $\mathrm{m} / \mathrm{z}$ $285.1-m / z 270.0$, and internal standard 6hydroxyflavone $\mathrm{m} / \mathrm{z} 241.0-\mathrm{m} / \mathrm{z} 137.0$.

Statistical analysis

We excluded four experimental units from sterilized treatments from all analyses because seedlings showed signs of infection, indicating non-sterile conditions during the experiment. For each of the other 15 -seed bio- assay units, we calculated the following values: percentage of germinated seeds, mean radicle length of germinated seeds, and percentage of infected seedlings (based on the number of infected seedlings divided by the number of germinated seedlings). We used ANOVA and Tukey's honest significant difference (HSD) test to analyze main and interactive effects of microbe treatments, residue fraction treatments, and time.

We also sought to quantify the relative contribution of microbes and residues to the weed-suppressive effect at each time point in our experiment. Following the procedure of Liebman and Sundberg (Liebman and Sundberg 2006a), we considered two different dimensions of weed suppressiveness of soils: germination inhibition (GI) and radicle elongation inhibition (RI). We compared different sets of treatments in order to partition GI and RI into three parts: microbe-only inhibition, residue-only inhibition, and the microbe-byresidue interaction. We estimated microbe-only inhibition by comparing live and sterile soil treatments in mesocosms receiving water-only additions (no residues). We estimated residue-only inhibition by comparing water-only and residue addition treatments in sterile soil (no microbes). We estimated the interaction, which represents non-additive effects due to the combination of live microbes and residues, by subtracting the microbe-only effects and residue-only effects from the total inhibition. To exemplify, the calculations for the various components of GI are as follows:

$$
\begin{aligned}
& \text { Microbe - only } \quad \text { - G I }=G_{\text {sterile soil+water-only }}{ }-G_{\text {live soil+water-only }} \\
& \text { Residue - only - G I }=G_{\text {sterile soil+water-only }}-G_{\text {sterile soil+residue }} \\
& \text { Interaction_GI }=G_{\text {sterile }} \text { soil+water-only }-G_{\text {live }} \text { soil+residue }- \text { Microbe-only_GI-Residue-only_GI }
\end{aligned}
$$

where $G$ was the mean germination percentage for all replicated units exposed to a particular treatment (i.e., $G_{\text {sterile soil + water-only }}$ was mean germination in sterile soil with distilled water). Note that the first two terms in the Interaction_GI estimate the total inhibition in treatments with live microbes and residues. We calculated RI using mean radicle length in place of $G$ in the formulas above. Values of GI and RI close to 0 indicate no effect on germination or radicle elongation. Positive values indicate inhibition (i.e., lower germination rate or shorter radicle lengths in treatments compared to controls). By looking at relative responses at each time point, we were able to remove any inherent variability due differences in seed biology and the experimental bioassay environment at the different time points, as these differences would also affect the water-only controls.

To explore overall patterns in chemical composition, we used principal components analysis ordination. We also fitted seed germination, radicle length, and days after incorporation on chemical composition ordination. All of these analyses used functions from package "vegan" in R (Oksanen et al. 2009).

The importance of individual allelochemicals on germination and growth was evaluated using partial least 
squares regression (PLSR, also commonly known as latent structure regression (Carrascal et al. 2009)) with a variable selection method. We used PLSR to model germination percentage or radicle length as a function of the multivariate HPLC data. Conceptually, PLSR is similar to using a principal components analysis ordination of the HPLC data to construct a set of orthogonal "latent variables" representing variation in chemical composition; these latent variables are then used as independent variables in regressions against a response variable. However, unlike principal components analysis, the ordination in PLSR creates latent variables that maximize the covariance between the chemical composition data and the response variable (germination percentage or radicle length). We used variable importance in projection (VIP) as the variable selection method (Gosselin et al. 2010; Wold et al. 1993). The loading of individual chemical components on the latent variables can be used as a measure of the importance of each chemical component to seed germination or seedling radicle length. Variable importance was estimated by weighting the latent variable loading of each compound by the contribution of its latent variables to weed germination or radicle length. We accumulated the weighted loading of each variable from each component and considered variable importance larger than $10 \%$ as a selection threshold. PLSR was performed in $\mathrm{R}$ using function plsr() in the package "pls" (Mevik et al. 2007).

\section{Results}

Effects of cover crop residues and microbes on weed suppression

Microbe and residue fraction treatments differed significantly with respect to weed seed germination and radicle length, and the interaction was also significant (ANOVA, $p$ value $<0.01$ for all comparisons). Microbes demonstrated high weed suppression potential in the absence of any residue fractions. In water-only control treatments, seed germination (Fig. 1) and radicle length (Supplemental Fig. 1) were consistently reduced by about $50 \%$ in live soil compared to sterilized soil ( $p$ value $<0.05$ ). The various residue fractions strongly reduced seed germination and seedling growth when compared to water-only controls, particularly in the early portions of the experiment (Fig. 1, S1). However, the presence of a live microbial community sometimes dramatically reduced the effectiveness of residue treatments. For fresh residue treatments, seed germination rates in live and sterile soil were similar for much of the experiment, but the presence of a live microbial community allowed for twice as much seed germination than sterile soil on day 30 (Fig. 1b). For soil receiving watersoluble extracts, seed germination was significantly higher (more than $60 \%$ ) in live soil than sterilized soil on days 2 and 4; after day 16, this relationship was reversed, with sterile soil having a higher germination rate than soil with a live microbial community (Fig. 1c). For straw residue treatments, seed germination rate was higher in sterilized soil than live soil with the exception of days 2 and 4 (Fig. 1d). The effects of time and treatments on radicle length were generally similar to what we found for seed germination (Supplemental Fig. 1).

The relative strengths of microbe-only suppression, residue-only suppression, and their interaction varied dynamically over time and across the different residue fractions (Fig. 2). Microbe-only inhibition was relatively stable over time (Fig. 2). The residue-only GI of fresh residues was consistently high over the entire experimental period. In contrast, the residue-only GI of watersoluble extracts and straw residues were high for the first 4 days of the experiment, and then, GI declined to very low levels for both of these fractions. The microbe-byresidue interaction almost always decreased the GI for all fractions (Fig. 2). The interaction resulted in a very large reduction in GI for water-soluble extracts and live microbes in the first 2 and 4 days of the experiment. In contrast, the interaction term gradually reduced the effects of microbes and fresh residues over the course of the experiment. The temporal and treatment-level patterns of RI were generally very similar to those of GI (Supplemental Fig. 2), but the microbe-by-residue interaction resulted in stronger reductions to RI than GI.

\section{Microbial disease incidence}

Microbial infection of seedlings (Supplemental Fig. 3) was a post-germination suppressive factor. We did not find infected seedlings in sterile soil treatments, except in the case of four bioassays, which were excluded from all statistical analyses (see Materials and methods). Across all non-sterile treatments, infected seedlings were on average $27 \mathrm{~mm}$ shorter than uninfected seedlings ( $p$ value $<0.001$ by $t$ test). We found microbial infection of seedlings in all non-sterile treatments, 
Fig. 1 Germination inhibition by red clover residues and soil microorganisms varies over time. Percentage of germinating mustard seeds in sterilized and live soil is shown for treatments exposed to a water, $\mathbf{b}$ watersoluble extracts, $\mathbf{c}$ fresh residues, and $\mathbf{d}$ straw residues. Error bars are standard errors from ten replicate analyses. Stars indicate comparisons that were determined to be significantly different at alpha $=0.05$ by a Tukey's HSD test

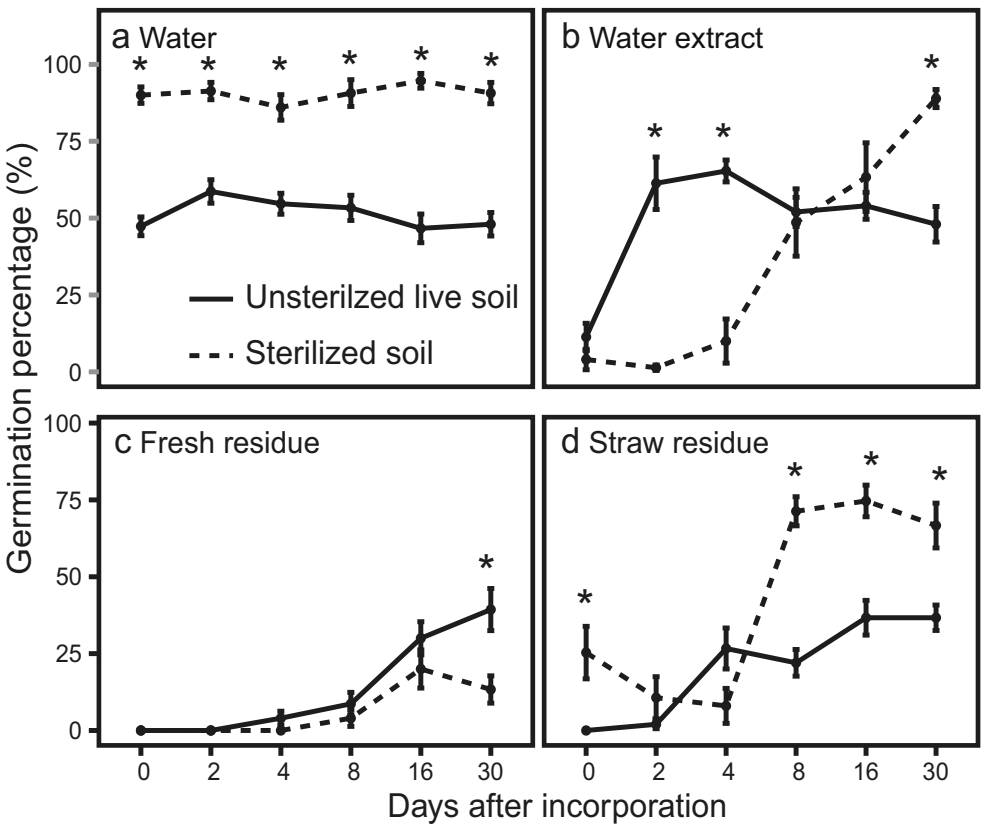

although the percentage of infected seedlings varied across treatments and over time (Fig. 3). Seedlings were fully infected in live soil with distilled water, but fewer than $50 \%$ of seedlings were infected in treatments with straw or fresh residues until day 8 . By day 16 , the infection rate of seedlings was higher than $80 \%$ in all treatments.

Total phenol content and weed suppression

Soil total phenols were negatively correlated with weed germination (Fig. 4) and radicle length (Supplemental Fig. 4). The threshold phenol concentration for complete suppression of seed germination was about $20 \mathrm{ng}$ per gram soil. For low concentrations of soil phenol, the presence of a live microbial community resulted in lower germination rates than sterile soil with similar phenol concentrations (Fig. 4).

\section{Allelochemical composition}

Different fractions of residues released different kinds of phenolic compounds into the soil (Figs. 5 and 6). Fresh residues and water-soluble extracts contained formononetin as the single dominant compound, while straw residues released roughly equal amount of formononetin, biochainin A, and prunetin (Fig. 6). Each of the phenolic compounds assayed here was negatively correlated to weed germination rate and radicle length. Genistin and daidzin, which are the 7-O-beta-Dglucoside derivatives of genistein and daidzein, were relatively high in soil with fresh residues and aqueous extracts. Genistein, prunetin, and biochanin A were relatively high in soil with straw residues.

The phenolic composition of all residue fractions converged over time to the water-only composition (Fig. 5b), which contained undetectable concentrations of phenolics (Fig. 6). This convergence happened more quickly in the live soil than in the sterilized soil. Allelochemicals from soil with straw residues increased from day 0 to day 2 , and then, they decreased more slowly than in any other treatment for the duration of the experiment.

Four chemicals were identified as potentially important weed-suppressive agents. Based on PLSR loadings, formononetin was the most potent weed-suppressive chemical in fresh residues and water-soluble extracts (Fig. 7). Biochainin A and prunetin were the most suppressive chemicals in the straw fraction. Calycosin was also found to contribute to weed suppression in water-soluble extracts and straw residues (Fig. 7).

\section{Discussion}

Because cover crop allelochemical effects are often transient and modified by soil microbes, it has been 


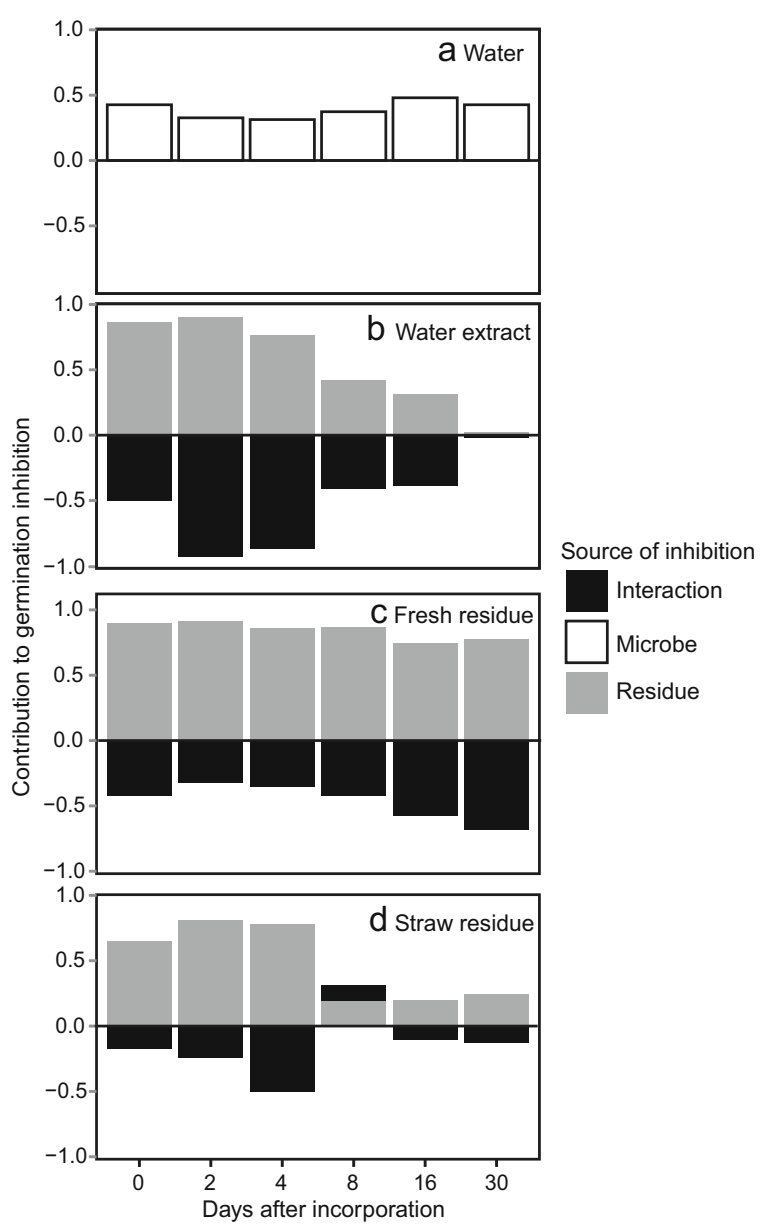

Fig. 2 Antagonistic interactions between soil microorganisms and red clover residues differ between residue fractions. Bars indicate the strength of microbe-only, residue-only, and microbe-byresidue contributions to germination inhibition

challenging to consistently apply cover crop-derived allelochemicals to weed control (Jilani et al. 2008; Macias et al. 2007). Here, we have demonstrated that both red clover residues and resident soil microbial communities have high potential to inhibit germination and growth of a common agricultural weed. However, these two sources of weed suppression interact antagonistically, such that the combined effects of soil microorganisms and red clover residues were smaller than what would be expected based on their separate contributions (Fig. 2, S2). The relative strength of the microbe-by-residue interaction varied over time and across treatments representing different components of red clover residues. Here, we discuss the dynamics of this non-additive microbe and residue combination, calling attention to the specific microbial interactions with cover crop residues and their associated allelochemicals that shape the effectiveness of green manure as a weed control strategy.

Microbial interactions with water-soluble allelochemials

Previous work on cover crop-associated allelochemicals has focused on the water-soluble components, which can be easily extracted from plant tissue and used in laboratory-based experiments (Liebman and Sundberg 2006a; Ohno and Doolan 2001). While our results agree with these previous studies that water-soluble extracts contain bioactivity that inhibits seed germination, we found that this bioactivity disappears very rapidly in the presence of a live microbial community (Fig. 1c). The antagonistic microbe-by-residue interaction was sufficient to completely negate the germination suppression potential of water-soluble extracts by the second day of our experiment, and this strong, negative interaction persisted for at least 30 days (Fig. 2). The rapid onset of a strongly antagonistic microbe-by-extract effect indicates that a focus on easily extractable chemical components of cover crop residues may overestimate their potential for weed suppression in natural settings with soil microorganisms present, and our results underscore the message of previous researchers that soil microorganisms are understudied but critically important mediators of important exterminators of allelopathic activity (Inderjit 2005; Inderjit et al. 2005).

This antagonistic microbe-by-extract interaction may indicate microbial degradation of phytotoxic compounds. Isoflavone allelochemicals, like those under consideration here, represent a rich carbon source for rhizobacteria (e.g., Actinobacteria and alpha- and gamma-Proteobacteria) capable of dehydroxylation and fission of the $\mathrm{C}$ rings, and some pathogenic fungi are also capable of detoxifying these compounds (Shaw et al. 2006). Formononetin can be rapidly degraded in soil with a lag time of approximately $24 \mathrm{~h}$ (Shaw and Hooker 2008), and many microbes are capable of hydrolyzing isoflavones into less soluble, less bioactive forms (Shaw et al. 2006). Therefore, the rapid loss of suppression in live microbe treatments is likely to be the result of rapid microbial degradation of the watersoluble components of red clover residues (Inderjit 2005; Inderjit et al. 2004). In line with this interpretation, we found that the profile of soil phenolic compounds in treatments with water-soluble extracts and live microbes was almost identical to that of wateronly controls by day 2 (Fig. 5b). In addition, the 


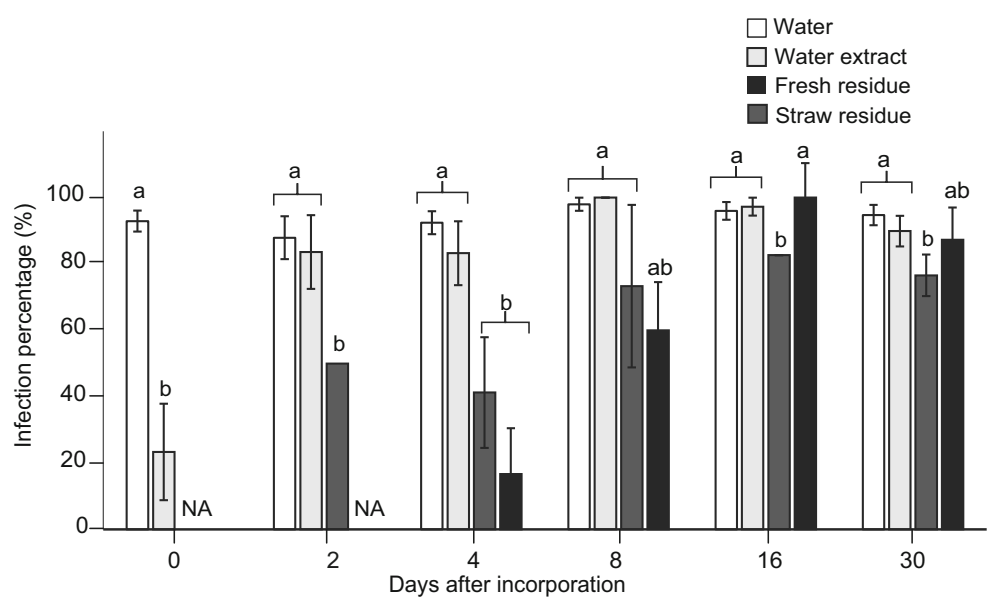

Fig. 3 Red clover residues inhibit seedling infection. Seedling infection percentage of mustard in live soil is shown for treatments exposed to water, water-soluble extracts, fresh residues, and straw residues. Infection percentage was measured by the number of infected seedlings divided by the total number of germinated

concentrations of red clover isoflavones in watersoluble extract treatments were lower in the presence of live microbes than in sterilized soils (Fig. 6). However, it is also possible that the water-soluble extracts negatively affected the soil microbial community, which we found to be naturally capable of germination suppression (Fig. 1a). Many red clover phenols, particularly isoflavones, have antimicrobial effects (Reynolds et al. 2003) and can inhibit the growth of microbial pathogens (Daayf et al. 2012). We note that the negative

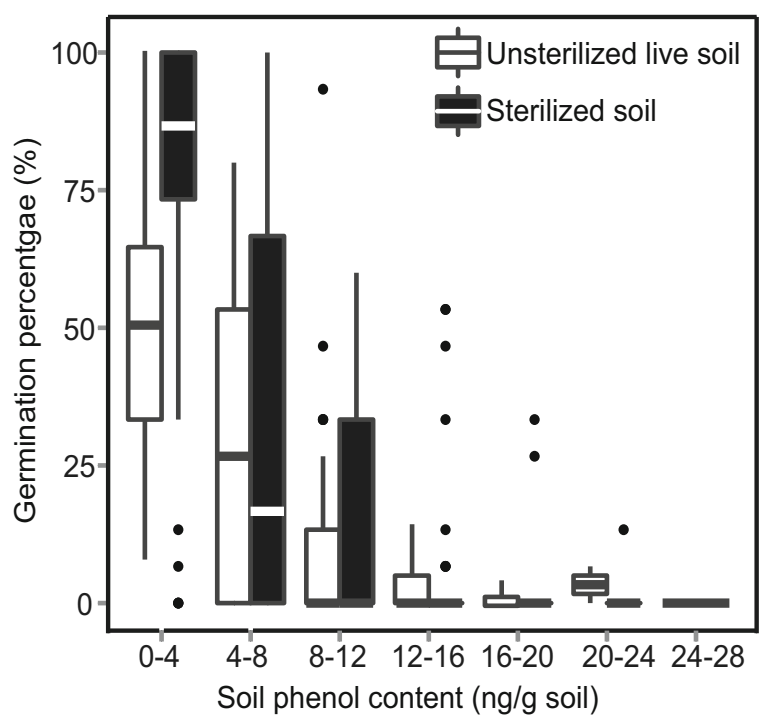

Fig. 4 Germination is inhibited by high concentrations of soil phenols seedlings in one bioassay. $N A$ indicates that no infection data was available because no seeds germinated at these time points. Error bars are standard errors from ten replicate analyses. Different lowercase letters were determined to be significantly different at alpha $=0.05$ by a Tukey's HSD test

microbe-by-extract interaction exceeded the extractonly suppression of seedling growth for much of the experiment (Fig. S2), and this means that at least a portion of the negative microbe-by-extract interaction must have come from a reduction in microbial capacity for seedling growth suppression. We also note that seedlings in water-only control treatments showed signs of infection throughout the experiment, but pathogenic attack on seedlings was low in all of the extract and residue treatments in the early portions of the experiment (Fig. 3). This may reflect the antimicrobial nature of residue-derived chemicals, but it may also indicate that residues provided an additional resource for soil microorganisms (Blum et al. 1993), resulting in a lower initial attack rate on emerging seedlings.

Several workers have proposed that allelochemicalinduced damage to seedlings can stimulate microbial attack (Chandler and Daniell 1974; Patrick et al. 1964; Toussoun and Patrick 1963), and Mohler and colleagues (Mohler et al. 2012) interpreted lower weed emergence in their live soil versus sterilized soil treatments to be the a signature of pathogenic weed suppression. In contrast to this previous work and in contrast to our hypothesis of synergistic pathogen activity, our results provide no evidence of pathogen stimulation by residues or residuederived chemicals. These discrepancies may be due to differences in microbial community composition or to methodological differences leading to different soil allelochemical concentrations. Our results indicate that microbial weed suppression was most important at the 


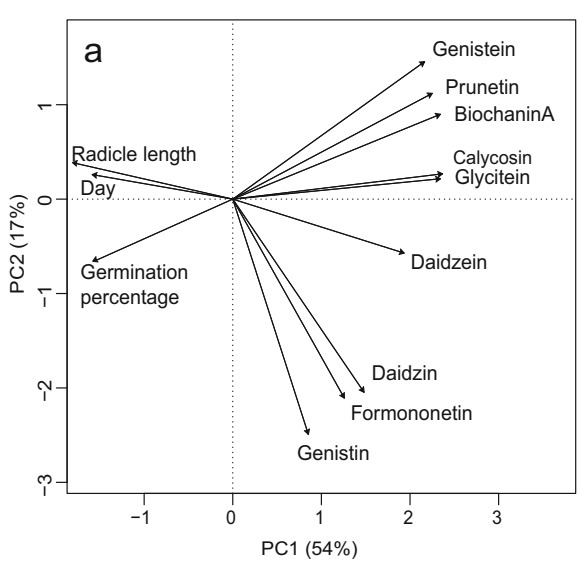

Fig. 5 Soil chemistry differs between residue fraction treatments. All panels were derived from a single principal components analysis of HPLC-derived isoflavone concentrations in soil. a The loadings of various isoflavone compounds on the ordination axes, as well as the loadings of the two main response variables

very lowest soil phenol concentrations (Fig. 4, S4), and it is possible that there is a "sweet spot" in allelochemical concentration at which pathogen stimulation is greater than antimicrobial inhibition. Whether or not farmers can manage soils, cover crop residues, and cash crop planting around such a sweet spot is an open question, and its answer may depend on the combined influences of residue chemical composition, the method of residue incorporation, and the biological properties of the soil microbial community.

\section{Microbial interactions with solid residue fractions}

In contrast to the rapid loss of bioactivity that we found for water-soluble extracts, we found that fresh red clover residues provided prolonged suppression of weed germination, and the presence of live microorganisms did not diminish this suppression for the first 16 days of the experiment (Fig. 1b). The combination of fresh red clover residues and a live microbial community represents our most field-relevant treatment, and so the microbe-by-residue interaction (Fig. S2) can shed light on in-field dynamics related to soil chemistry and ecology. We propose that fresh red clover residues served as a reservoir of allelochemicals throughout our experiment and that these allelochemicals were released in sufficient quantities to inhibit seed germination and seedling growth over a prolonged period of time. The phenolic profile of soil with fresh residues took 16 days to converge on the water-only controls (Fig. 5), and the concentrations of isoflavones in the fresh residue treatment equaled or exceeded the concentrations found in the water-soluble extract treatment, even when live microbial communities were present (Fig. 6). We suggest that the allelochemicals in fresh residues were more protected from microbial degradation than when they were added as extracts, giving fresh red clover residues a longer lasting suppressiveness. While we used only the aerial parts of the red clover plant for our experiment, the roots of the plant would also be present in green manured systems; because these roots can also be a source of allelochemicals (Forney and Foy 1985; Inderjit et al. 2005), they may provide additional weed suppression that what we can document here.

We identified formononetin as the most important allelochemical in the fresh residue treatments (Fig. 7), in agreement with previous work demonstrating the potency of formononetin as a plant growth inhibitor (Liu et al. 2013). We note that formononetin was also the most important allelochemical in water-soluble extracts, and this suggests that fresh residues and watersoluble extracts have similar chemical modes of action, but the longer - lasting nature of the fresh residue effect may be due to the slow release of this chemical over time. Interestingly, the soil concentration of formononetin was higher in the fresh residue plus live microbe treatment than it was in the sterile water-soluble extract treatment on day 8 (Fig. 6); at this time, the fresh residue treatments (live and sterile) were highly suppressive of seed germination (Fig. 1b), while the water- 
Fig. 6 Isoflavone content differed between treatments and over time. Stacked bars indicate the relative concentrations of nine major isoflavone components in sterilized and live soils for treatments exposed to water, water-soluble extracts, fresh residues, and straw residues

Fig. 7 Different isoflavones were associated with weed suppression in different treatments. The height of bars shows the loadings of various isoflavone compounds on a PLSR axis describing the relationship between isoflavone concentration and seed germination rate. The negative loadings indicate that all of these isoflavones inhibited seed germination
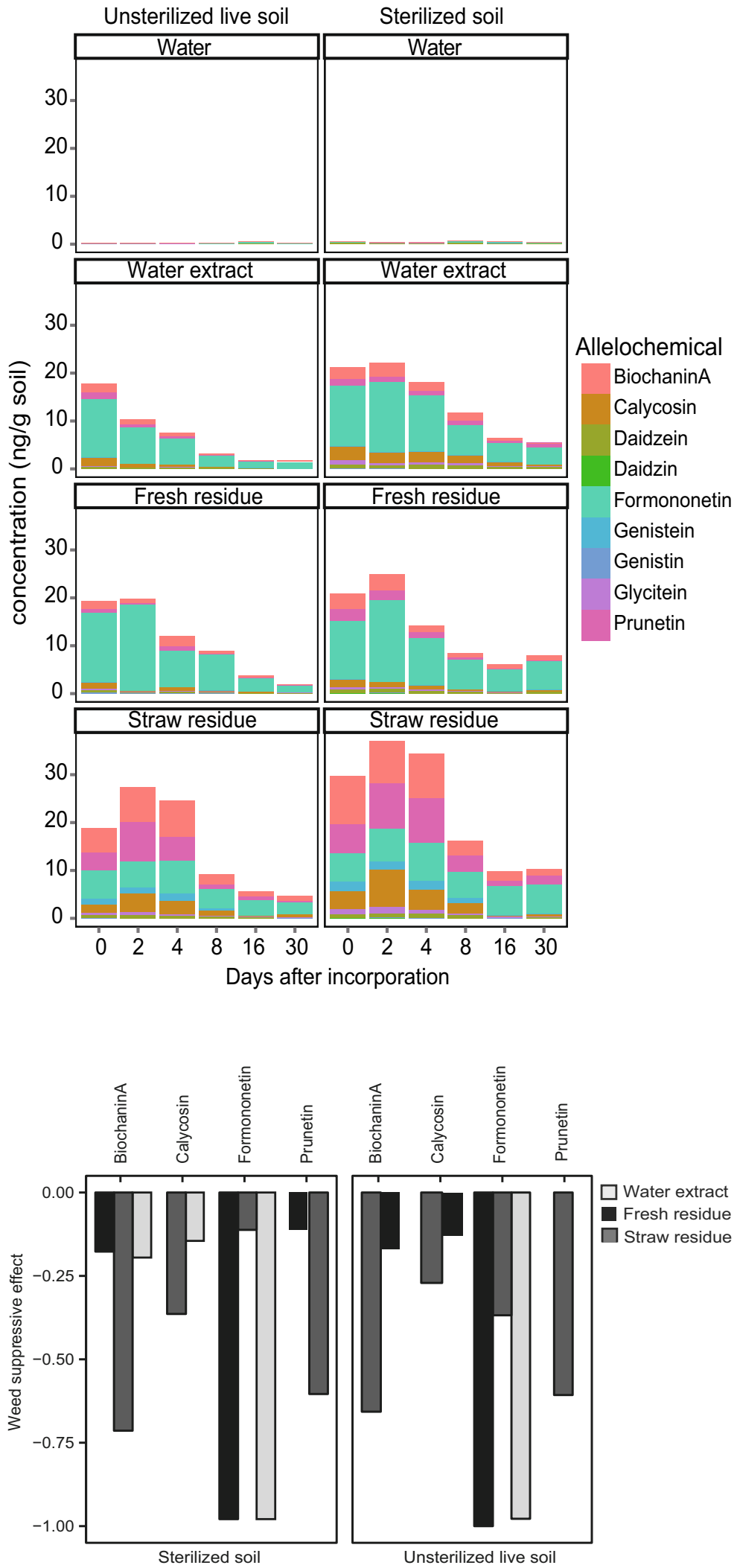
soluble extract treatments were losing suppressiveness (Fig. 1c).

Fresh red clover residues provided almost total germination suppression on their own for the first 8 days of the experiment, leaving no room for any additional or synergistic effects of microorganisms; note that the negative interaction is essentially equal in magnitude to the microbe-only suppression for the first 8 days of the experiment (Fig. 2). Our results agree with previous reports of potent red clover residue affects on wild mustard (Ohno and Doolan 2001) and common lambsquarters emergence (Dyck and Liebman 1994). We found some seed germination in fresh residue treatments starting on day 16 (Fig. 1), by which time the antagonistic microbe-by-residue interaction exceeded the microbe-only effect (Fig. 2). We propose that between day 8 and day 16, the rate of microbial degradation of allelochemicals exceeded the rate of release from the residues, resulting in a sufficiently low bioactivity for some seeds to germinate successfully. Other research suggests that this slow degradation of residue-derived allelochemicals may provide some degree of seed toxicity over 5 weeks (Ohno and Doolan 2001).

Some of the prolonged suppressiveness of red clover residues may have been due to the presence of relatively insoluble phytotoxic compounds in the solid portions of the residues. Phenolic compounds are found in both free and bound forms in plant tissue (Lin et al. 2000), and many bound phenolic compounds are water insoluble and difficult to extract even with organic solvents (Tebeest et al. 1992). We found that the addition of straw residues - which had been leached of water-soluble compounds - suppressed seed germination over a prolonged period of time (Fig. 1), a result that is consistent with previous evidence of "physical" suppression by a number of different leached cover crop residues (Creamer et al. 1996). The chemical profile in soils with straw residues was unlike that of any other treatment (Fig. 5), including much higher concentrations of biochanin A, calycosin, and prunetin than in other treatments (Fig. 6) and also higher concentrations of the nonglucoside and less water-soluble (Stancanelli et al. 2007) isoflavones genistein, daidzein, and glycitein. Biochanin A (Shajib 2012) and daidzein (Tamura et al. 1969) can inhibit plant growth, while genistein can inhibit root absorption of nutrients (Stenlid 1961); the allelochemical effects of the other compounds have been poorly investigated. Since biochanin A, calycosin, and prunetin persisted in sterile soil treatments at relatively high concentrations over the course of the experiment (Fig. 6), it may be that the $\sim 25 \%$ suppression of seed germination found in sterilized straw residue treatments at the end of our experiment (Figs. 1 and 7 ) is due to these isoflavones. However, only the combination of live microbes and straw residues showed the prolonged, high rate of suppression that we found with fresh red clover residues (Fig. 1), and we found low concentrations of most isoflavones in these treatments on days 16 and 30 (Fig. 6) even though weed suppression remained relatively high. We note the relatively small microbe-by-straw interaction in the latter half of our experiment (Fig. 2), and we propose that both chemical and microbial activity were necessary for weed suppression by straw residues. Future research that focuses on microbial interactions with bound chemicals in solid residues may lead to practices that can prolong cover crop suppression of weeds beyond the residence time of water-soluble allelochemicals in soils.

\section{Non-interactive effects}

While we have focused on residue-microbe interactions here, a consideration of residue-only and microbe-only dynamics suggests that there is more to be learned through further study. For example, the residue-only suppression (Fig. 2) and isoflavone profiles (Fig. 6) changed considerably even in our sterile soil treatments, with sterile soil isoflavone profiles converging on wateronly controls and live soil profiles (Fig. 5). We can only speculate on the reasons that allelochemical concentrations and phytotoxicity decreased in our sterile soils. It is difficult to completely sterilize soils in an autoclave (Nowak and Wronkowska 1987). While we found no infected seedlings in 236 out of 240 sterile soil bioassays, we cannot rule out the possibility that microbial regrowth of allelochemical-degrading organisms was responsible for the loss of isoflavones and weed suppression in our sterile soils. If this is the case, it underscores just how quickly allelochemical weed suppression can disappear under the pressure of a small but growing microbial population. Another plausible explanation is that dynamics in sterile soils was caused by sorption of bioactive chemicals to clay minerals in the soils (Shaw and Hooker 2008). A full understanding of this kinetics can provide important context and boundary conditions for green manure-based weed control. 
In contrast, microbial weed suppression showed a surprising lack of dynamics. Without the addition of cover crop residues, the soil microbial community consistently suppressed seed germination (Fig. 1) and seedling growth rates (Fig. S1) throughout the entire experiment, and even with the addition of various residue fractions, weed suppression in live soils tended to converge on levels found in live soil + water controls (e.g., Fig. 1a). This "baseline" level of microbial weed suppression may indicate that the responsible populations were resistant or non-responsive to the treatments we imposed here. If so, then future work should focus on identifying these weed-suppressive agents and characterizing ways to stimulate their activity. On the other hand, it may be the case that our soil communities were dynamic, but weed-suppressive activity was due to many functionally redundant taxa. This would imply that microbial weed suppression is an emergent property of the soil community; in this case, it will be important to understand what factors constrain this property and how it can be enhanced.

\section{Conclusions}

The dynamics of this non-additive microbe and residue combination call attention to the nature of specific microbial interactions with cover crop residues and their associated allelochemicals, and understanding these interactions may lead to improved biocontrol of weeds from these two sources. We found a negative interaction between microbial activity and cover crop-derived weed suppression, but the nature of this interaction was dynamic in time. As a result, overall weed suppression shifted over time from predominantly chemical phase to a predominantly microbial phase. Solid residues can prolong this initial phase, possibly by protecting watersoluble allelochemicals from microbial attack and by serving as a reservoir for water-soluble and waterinsoluble compounds. The loss of residue-derived suppression over time suggests that allelochemical degradation is a major role for microbes. However, we found a consistent and high potential for microbial suppression over the course of the experiment, meaning that microbes can also play beneficial roles in weed suppression. A deeper insight into microbial community composition in cover-cropped systems may lead to a better understanding of how these beneficial roles can be stimulated to help maximize weed control.
Acknowledgments We thank A. Davis, A. Kent, A. Leakey, C. Soman, D. Li, A. Beck, D. Cohen, N. Stevenson, M. Scott, G. Rienne, and S. Chavez for valuable feedback during the preparation of this manuscript. This research was funded by the USDACSREES (Project ILLU-875-317) and by the USDA-NIFA (Agriculture and Food Research Initiative Climate Change Mitigation and Adaptation in Agriculture Grant 2011-67003-30343).

Open Access This article is distributed under the terms of the Creative Commons Attribution 4.0 International License (http:// creativecommons.org/licenses/by/4.0/), which permits unrestricted use, distribution, and reproduction in any medium, provided you give appropriate credit to the original author(s) and the source, provide a link to the Creative Commons license, and indicate if changes were made.

\section{References}

Ainsworth EA, Gillespie KM (2007) Estimation of total phenolic content and other oxidation substrates in plant tissues using Folin-Ciocalteu reagent. Nat Protoc 2:875-877. doi:10.1038/ nprot.2007.102

Barnes JP, Putnam AR (1986) Evidence of allelopathy by residues and aqueous extracts of rye (Secale cereale). Weed Sci 34: 384-390

Barnes JP, Putnam AR, Burke BA, Aasen AJ (1987) Isolation and characterization of allelochemicals in Rye Herbage. Phytochemistry 26:1385-1390. doi:10.1016/S00319422(00)81818-X

Blum U, Gerig TM, Worsham AD, King LD (1993) Modification of allelopathic effects of P-Coumaric acid on morning-glory seedling biomass by glucose, methionine, and nitrate. J Chem Ecol 19:2791-2811. doi:10.1007/Bf00980584

Carrascal LM, Galván I, Gordo O (2009) Partial least squares regression as an alternative to current regression methods used in ecology. Oikos 118:681-690. doi:10.1111/J.16000706.2008.16881.X

Chandler WA, Daniell JW (1974) Effect of leachates from peach soil and roots on bacterial canker and growth of peach seedlings. Phytopathology 64:1281-1284

Charudattan R (2001) Biological control of weeds by means of plant pathogens: significance for integrated weed management in modern agro-ecology. BioControl 46:229-260. doi: 10.1023/A: 1011477531101

Conklin AE, Erich MS, Liebman M, Lambert D, Gallandt ER, Halteman WA (2002) Effects of red clover (Trifolium pratense) green manure and compost soil amendments on wild mustard (Brassica kaber) growth and incidence of disease. Plant and Soil 238:245-256

Creamer NG, Bennett MA, Stinner BR, Cardina J, Regnier EE (1996) Mechanisms of weed suppression in cover crop-based production systems. HortScience 31:410-413

Daayf F, El Hadrami A, El-Bebany AE, Henriquez MA, Yao Z, Derksen H, El-Hadrami I, Adam LR (2012) Phenolic compounds in plant defense and pathogen counter-defense mechanisms. Rec Adv Polyphen Res 3:191-208 
Dabney SM, Schreiber JD, Rothrock CS, Johnson JR (1996) Cover crops affect Sorghum seedling growth. Agr J 88: 961-970

Davis AS, Renner KA (2007) Influence of seed depth and pathogens on fatal germination of velvetleaf (Abutilon theophrasti) and giant foxtail (Setaria faberi). Weed Sci 55:30-35. doi:10. 1614/W-06-099.1

Dyck E, Liebman M (1994) Soil fertility management as a factor in weed control: the effect of crimson clover residue, synthetic nitrogen fertilizer, and their interaction on emergence and early growth of lambsquarters and sweet corn. Plant and Soil 167:227-237

Dyck E, Liebman M (1995) Crop-weed interference as influenced by a leguminous or synthetic fertilizer nitrogen source .2 . Rotation experiments with crimson clover, field corn, and lambsquarters. Agr Ecosyst Environ 56:109-120. doi:10. 1016/0167-8809(95)00644-3

Forney DR, Foy CL (1985) Phytotoxicity of products from rhizospheres of a sorghum-sudangrass hybrid (Sorghum bicolor $x$ Sorghum sudanense). Weed Sci 33:597-604

Gosselin R, Rodrigue D, Duchesne C (2010) A Bootstrap-VIP approach for selecting wavelength intervals in spectral imaging applications. Chemomet Intell Lab 100:12-21. doi:10. 1016/j.chemolab.2009.09.005

Harper SHT, Lynch JM (1982) The role of water-soluble components in phytotoxicity from decomposing straw. Plant and Soil 65:11-17. doi:10.1007/Bf02376798

Inderjit (1996) Plant phenolics in allelopathy. Botan Rev 62:186202. doi:10.1007/Bf02857921

Inderjit (2005) Soil microorganisms: an important determinant of allelopathic activity. Plant and Soil 274:227-236. doi:10. 1007/S11104-004-0159-X

Inderjit, Rawat DS, Foy CL (2004) Multifaceted approach to determine rice straw phytotoxicity. Can J Bot 82:168-176. doi:10.1139/B03-137

Inderjit, Weston LA, Duke SO (2005) Challenges, achievements and opportunities in allelopathy research. J Plant Int 1:69-81. doi:10.1080/17429140600622535

Jilani G, Mahmood S, Chaudhry AN, Hassan I, Akram M (2008) Allelochemicals: sources, toxicity and microbial transformation in soil-a review. Ann Microbiol 58:351-357

Kremer RJ (1993) Management of weed seed banks with microorganisms. Ecol Appl 3:42-52. doi:10.2307/1941791

Krenn L, Unterrieder I, Ruprechter R (2002) Quantification of isoflavones in red clover by high-performance liquid chromatography. J Chromatogr B 777:123-128. doi:10.1016/ S1570-0232(02)00079-X

Kruidhof HM, Bastiaans L, Kropff MJ (2009) Cover crop residue management for optimizing weed control. Plant and Soil 318: 169-184. doi:10.1007/s11104-008-9827-6

Levengood JM, Tam TM, Szafoni D (2010) A preliminary assessment of isoflavones in an agricultural environment. Illinois Sustain Tech Cent, Urbana, Illinois, US p 25. http://www.istc. illinois.edu/info/library docs/TR/TR42.pdf

Liebman M, Davis AS (2000) Integration of soil, crop and weed management in low-external-input farming systems. Weed Res 40:27-47

Liebman M, Davis AS (2009) Managing weeds in organic farming systems: an ecological approach. In: Francis C (ed) Organic farming: the ecological system. American Society of Agronomy, Madison
Liebman M, Dyck E (1993) Crop-rotation and intercropping strategies for weed management. Ecol Appl 3:92-122. doi:10. 2307/1941795

Liebman M, Sundberg DN (2006) Seed mass affects the susceptibility of weed and crop species to phytotoxins extracted from red clover shoots. Weed Sci 54:340-345

Lin LZ, He XG, Lindenmaier M, Yang J, Cleary M, Qiu SX, Cordell GA (2000) LC-ESI-MS study of the flavonoid glycoside malonates of red clover (Trifolium pratense). J Agr Food Chem 48:354-365. doi:10.1021/J9991002+

Liu Q, Xu R, Yan ZQ, Jin H, Cui HY, Lu LQ, Zhang DH, Qin B (2013) Phytotoxic allelochemicals from roots and root exudates of trifolium pratense. J Agr Food Chem 61:6321-6327. doi:10.1021/Jf401241e

Macias FA, Molinillo JMG, Varela RM, Galindo JCG (2007) Allelopathy - a natural alternative for weed control. Pest Manag Sci 63:327-348. doi:10.1002/Ps. 1342

Mevik BH, Wehrens R (2007) The pls package: principal component and partial least squares regression in R. J Stat Softw $18(2): 1-24$

Mirsky SB, Curran WS, Mortensen DM, Ryan MR, Shumway DL (2011) Timing of cover-crop management effects on weed suppression in no-till planted soybean using a roller-crimper. Weed Sci 59:380-389

Mohler CL, Dykeman C, Nelson EB, Ditommaso A (2012) Reduction in weed seedling emergence by pathogens following the incorporation of green crop residue. Weed Res 52: 467-477. doi:10.1111/j.1365-3180.2012.00940.x

Moore MJ, Gillespie TJ, Swanton CJ (1994) Effect of cover crop mulches on weed emergence, weed biomass, and soybean (Glycine-Max) development. Weed Technol 8:512-518

Moyer JR, Blackshaw RE, Smith EG, McGinn SM (2000) Cereal cover crops for weed suppression in a summer fallow-wheat cropping sequence. Can J Plant Sci 80:441-449

Nowak A, Wronkowska H (1987) On the efficiency of soil sterilization in autoclave. Zbl Mikrobiol 142:521-525

Ohno T, Doolan KL (2001) Effects of red clover decomposition on phytotoxicity to wild mustard seedling growth. Appl Soil Ecol 16:187-192

Ohno T, Doolan K, Zibilske LM, Liebman M, Gallandt ER, Berube C (2000) Phytotoxic effects of red clover amended soils on wild mustard seedling growth. Agr Ecosyst Environ 78:187-192

Oksanen J, Kindt R, Legendre P, O'Hara B, Simpson GL, Solymos P, Stevens HH, Wagner H (2009) Vegan: community ecology package. $\mathrm{R}$ Pack Ver 1:15-4

Patrick Z, Toussoun T, Koch L (1964) Effect of crop-residue decomposition products on plant roots. Annu Rev Phytopathol 2:267-292

Reynolds HL, Packer A, Bever JD, Clay K (2003) Grassroots ecology: plant-microbe-soil interactions as drivers of plant community structure and dynamics. Ecology 84:2281-2291

Rothrock CS, Kirkpatrick TL (1995) The influence of winter legume cover crops on soilborne plant pathogens and cotton seedling diseases. Plant Dis 79:167-171

Samedani B, Juraimi AS, Anwar MP, Rafii MY, Awadz SAS, Anuar AR (2013) Phytotoxic effects of Pueraria javanica litter on growth of weeds Asystasia gangetica and Pennisetum polystachion. Allelopath J 32:191-201

Seigler DS (1996) Chemistry and mechanisms of allelopathic interactions. Agron J 88:876-885 
Shajib MTI (2012) Isoflavonoid-biochanin A as an allelopathic agent for weed suppression: bioassays, LCMS-MS and principal component analysis. LAP Lambert Academic Publishing AG \& Co KG, Berlin, Germany

Shaw LJ, Hooker JE (2008) The fate and toxicity of the flavonoids naringenin and formononetin in soil. Soil Biol Biochem 40: 528-536. doi:10.1016/j.soilbio.2007.09.021

Shaw LJ, Morris P, Hooker JE (2006) Perception and modification of plant flavonoid signals by rhizosphere microorganisms. Environ Microbiol 8:1867-1880. doi:10.1111/j.1462-2920. 2006.01141.x

Singh HP, Batish DR, Kohli RK (2003) Allelopathic interactions and allelochemicals: new possibilities for sustainable weed management. Crit Rev Plant Sci 22:239-311. doi:10.1080/ 713610858

Stancanelli R, Mazzaglia A, Tornmasini S, Calabro ML, Villari V, Guardo A, Ficarra P, Ficarra R (2007) The enhancement of isoflavones water solubility by complexation with modified cyclodextrins: a spectroscopic investigation with implications in the pharmaceutical analysis. J Pharmaceut Biomed 44:980-984. doi:10.1016/j.jpba.2007.03.025

Stenlid G (1961) On the effects of some flavonoid pigments upon growth and ion absorption of wheat roots. Physiol Plant 14: 659-670

Tamura S, Chang C-F, Suzuki A, Kumai S (1969) Chemical studies on "clover sickness" part I. Isolation and structural elucidation of two new isoflavonoids in red clover. Agric Biol Chem 33:391-397

Teasdale JR (1996) Contribution of cover crops to weed management in sustainable agricultural systems. J Prod Agric 9:475479

Teasdale JR, Rice CP, Cai GM, Mangum RW (2012) Expression of allelopathy in the soil environment: soil concentration and activity of benzoxazinoid compounds released by rye cover crop residue. Plant Ecol 213:1893-1905. doi:10.1007/ s11258-012-0057-X

Tebeest DO, Yang XB, Cisar CR (1992) The status of biologicalcontrol of weeds with fungal pathogens. Annu Rev Phytopathol 30:637-657. doi:10.1146/annurev.py.30. 090192.003225

Toussoun TA, Patrick ZA (1963) Effect of phytotoxic substances from decomposing plant residues on root rot of bean. Phytopathology 53:265-269

Tsao R, Papadopoulos Y, Yang R, Young JC, McRae K (2006) Isoflavone profiles of red clovers and their distribution in different parts harvested at different growing stages. J Agr Food Chem 54:5797-5805. doi:10.1021/Jf0614589

Wardle D (1995) Impacts of disturbance on detritus food webs in agro-ecosystems of contrasting tillage and weed management practices. Advan Ecol Res 26:105-185

Weston LA (1996) Utilization of allelopathy for weed management in agroecosystems. Agr J 88:860-866

Williamson GB, Obee EM, Weidenhamer JD (1992) Inhibition of schizachyrium-scoparium (Poaceae) by the allelochemical hydrocinnamic acid. J Chem Ecol 18:2095-2105. doi:10. 1007/Bf00981930

Wilson M, Hirano SS, Lindow SE (1999) Location and survival of leaf-associated bacteria in relation to pathogenicity and potential for growth within the leaf. Appl Environ Microb 65: 1435-1443

Wold S, Johansson E, Cocchi M (1993) PLS — partial least squares projections to latent structures. 3D QSAR Drug Des 1:523550

Wortman SE, Francis CA, Bernards MA, Blankenship EE, Lindquist JL (2013) Mechanical termination of diverse cover crop mixtures for improved weed suppression in organic cropping systems. Weed Sci 61:162-170. doi:10.1614/WsD-12-00066.1 